\title{
重 \\ A GESTÃO DO CONHECIMENTO PARA O DESENVOLVIMENTO DE INOVAÇÕES EM UMA EMPRESA DE PEQUENO PORTE: O CASO DA BHS COMÉRCIO DE PRODUTOS PARA SAÚDE LTDA - EPP
}

\author{
Cibele Lopes Rizzuto de Oliveira \\ Mestre em Gestão e Estratégia pela Universidade Federal Rural do Rio de \\ Janeiro, Brasil. Analista de Planejamento no Instituto Nacional de \\ Propriedade Industrial, Brasil. \\ E-mail: cibele.rizzuto@gmail.com

\section{André Yves Cribb} \\ Doutor em Engenharia de Produção pela Universidade Federal do Rio de \\ Janeiro, Brasil. Professor da Universidade Federal Rural do Rio de Janeiro, \\ Brasil. Pesquisador da Embrapa, Brasil. \\ E-mail: andre.cribb@embrapa.br
}

\begin{abstract}
Resumo
O artigo busca entender como é realizada a gestão do conhecimento em uma empresa de pequeno porte, que gerou uma inovação que culminou em depósito de patente. Foi realizada pesquisa dentre as empresas participantes do Projeto Piloto de Exame Prioritário de Patentes, do ano de 2016, ano de criação do projeto, do Instituto Nacional da Propriedade Industrial (INPI). Dentre as empresas participantes do projeto, foi entrevistada a empresa BHS, por ter depositado mais de um pedido de patente. Para esse estudo de caso, foi realizada entrevista pessoal, com um dos diretores e sócio da empresa, nas instalações em São Paulo, em 2018. A entrevista permitiu concluir que a empresa realiza internamente a gestão do conhecimento, embora sem que haja metodologia específica, porém valoriza o conhecimento científico advindo de profissionais altamente capacitados, como mestres e doutores e entende a crucial importância da gestão do conhecimento no desenvolvimento de inovações. As inovações desenvolvidas pela empresa são produtos de média e alta complexidade, e que por conta disso requerem profissionais altamente capacitados, durante a pesquisa e desenvolvimento. Para busca desses profissionais, utiliza-se de mecanismos como a interação entre a empresa e a universidade e também procura outras parcerias e associações, até mesmo com outras empresas. Dessa forma, a empresa pode inovar nos seus produtos e processos, a ponto de culminar em um depósito de patente. A pesquisa demonstrou a importância da parceria com a universidade e o grande envolvimento com a gestão do conhecimento com a valorização do conhecimento dos seus profissionais.
\end{abstract}

Palavras-chave: Gestão do Conhecimento. Inovação. Patentes.

\section{THE MANAGEMENT OF KNOWLEDGE FOR THE DEVELOPMENT OF INNOVATIONS IN A SMALL BUSINESS COMPANY: \\ THE CASE OF BHS TRADE OF PRODUCTS FOR HEALTH LTDA - EPP}

\begin{abstract}
The article seeks to understand how knowledge management is performed in a small company, which generated an innovation that culminated in patent filing. A survey was carried out among the companies participating in the Priority Patent Examination Pilot Project, from the year 2016, year of creation of the project, from the National Institute of Industrial Property (INPI). Among the companies participating in
\end{abstract}

Perspectivas em Gestão \& Conhecimento, João Pessoa, v. 8, número especial, p. 4-20, out. 2018. DOI: http://dx.doi.org/10.21714/2236-417X2018v8nep4 
the project, BHS was interviewed for having filed more than one patent application. For this case study, a personal interview was conducted with one of the directors and partner of the company, at the premises in São Paulo, in 2018. The interview allowed to conclude that the company internally performs knowledge management, although there is no specific methodology, but it values the scientific knowledge coming from highly qualified professionals such as masters and doctors and understands the crucial importance of knowledge management in the development of innovations. The innovations developed by the company are products of medium and high complexity, and that for this reason require highly qualified professionals during the research and development. In order to find these professionals, it uses mechanisms such as the interaction between the company and the university and also looks for other partnerships and associations, even with other companies. In this way, the company can innovate in its products and processes, to the point of culminating in a patent deposit. The research demonstrated the importance of the partnership with the university and the great involvement with knowledge management with the appreciation of the knowledge of its professionals.

Keywords: knowledge management. Innovation. Patents.

\section{INTRODUÇÃO}

O conhecimento que vem de fora, para dentro das organizações e que retornam como novos produtos, serviços ou sistemas, a chamada conversão do conhecimento é que levou as empresas japonesas ao sucesso (NONAKA; TAKEUCHI, 1997). Dessa forma, sabemos que o conhecimento deve ser compartilhado dentro das organizações. Segundo Probst et al. (2009), o conhecimento coletivo, que é mais do que a soma do conhecimento individual, é particularmente importante para a sobrevivência das organizações a longo prazo. O processo de criação do conhecimento organizacional contempla a etapa de socialização, ou seja, o compartilhamento do conhecimento, internamente na empresa.

Por outro lado, as inovações representam o conhecimento em forma de aplicações práticas, por meio de novos produtos ou serviços. O processo através do qual o novo conhecimento é criado dentro da organização - sob a forma de novos produtos, serviços ou sistemas - e o processo de geração do conhecimento facilita o desenvolvimento de atividades inovadoras (NONAKA; TAKEUCHI, 1997).

Porém, conforme observam De Almeida e Ferraz Cario (2013) há diferenças entre os processos de inovação nas grandes e pequenas empresas. Naquelas, há esforços de capacitação tecnológica a partir de gastos anuais em P\&D e investimentos em recursos humanos, enquanto a maioria das MPEs realizam processos inovativos a partir de mecanismos informais de aprendizado, com relações interativas fortes com o segmento de ferramentarias (moldes) e com os clientes industriais presente na região (Klug, 2001; Resende e Gomes, 2003).

Partindo dessas premissas, o presente artigo tem como objetivo entender como acontece a gestão do conhecimento de forma a facilitar e promover a inovação que culminou em um depósito de patente, dentro de uma empresa de pequeno porte. Para o desenvolvimento do artigo optamos por um estudo de caso, realizado com a empresa BHS Comércio de Produtos Para Saúde Ltda - EPP (Brasil Health Service ${ }^{\circledR}$ ). Para o estudo de caso foi realizada entrevista com um dos diretores e sócios da empresa, nas instalações em São Paulo, no mês de março do ano de 2018. A entrevista pretendia elucidar como o conhecimento é construído e gerido numa pequena empresa e buscar indícios e características a respeito de empresas com potencial para a inovação.

A empresa BHS foi escolhida com base na relação de micro e pequenas empresas que realizaram depósito de patente no INPI, por meio do Projeto Piloto de Exame Prioritário de Patentes, no ano de 2016. Naquele ano, foram objetos de exame prioritário apenas 76

Perspectivas em Gestão \& Conhecimento, João Pessoa, v. 8, número especial, p. 4-20, out. 2018. 
pedidos, dentre esses pedidos se encontrava o da empresa BHS. A entrevista foi realizada com um dos diretores e sócios da empresa, nas instalações da BHS, em São Paulo, em março de 2018. Também cabe ressaltar que a escolha se baseou na localização, a facilidade de contato e interesse da empresa em participar do estudo.

A análise dos dados ocorreu com base na entrevista realizada, descrevendo as principais informações colhidas e, conforme ressalta Yin (2001), organizar os dados com base nas propostas teóricas e buscando relações entre o observado na prática e o relatado na teoria, buscando identificar padrões de relacionamento entre os dados.

Dessa forma, o artigo se divide em três partes: na primeira é apresentado o referencial teórico acerca da gestão do conhecimento, suas funções, a gestão da inovação e o papel das patentes para as pequenas empresas; na segunda é apresentada uma análise das informações obtidas por meio da entrevista, com a empresa BHS, de forma a confrontar os achados empíricos com os autores revistos, a respeito da importância do conhecimento na sociedade atual e seu potencial para a inovação; e na terceira e última parte é apresentada a conclusão do artigo que avalia o cumprimento dos objetivos propostos.

\section{REFERENCIAL TEÓRICO}

\subsection{0 conhecimento e os mecanismos para sua gestão}

Como ressaltam Bem e Ribeiro Júnior (2006), o conhecimento é fundamental para as organizações e aquelas empresas que o detém e que permitem que haja espaço para que novos conhecimentos sejam criados, possuem maior vantagem competitiva, pois a tecnologia pode ser copiada, mas é necessário conhecimento para utilizá-la.

Além disso, a Gestão do Conhecimento deve levar em consideração as necessidades do ambiente competitivo e as necessidades de conhecimento, tanto individuais como coletivas (TERRA, 2005).

Porém, como apontado por Bem e Ribeiro Júnior (2006), disponibilizar o conhecimento tácito de forma explícita, bem como organizá-lo é a maior dificuldade que as empresas enfrentam.

Como destacado por Silva (2002), a diferença existente entre os formatos de conhecimento (tácito e explícito) pode ser sintetizado na linguagem formal, enquanto o conhecimento tácito é difícil de ser traduzido para uma linguagem formal, por ser pessoal e possuir características intangíveis, o conhecimento explícito pode assumir um aspecto formal, por meio de manuais, especificações, entre outros. A interação entre os dois formatos vão convergir na dinâmica da criação do conhecimento na organização.

Isso nos leva ao modelo espiral de criação do conhecimento de Nonaka e Takeuchi (1997), conforme figura 1 abaixo, que apresentam um modelo de cinco fases do processo de criação do conhecimento organizacional, qual seja: começa com o compartilhamento do conhecimento tácito, que corresponde à socialização, pois, inicialmente, o conhecimento rico e inexplorado que habita os indivíduos precisa ser amplificado dentro da organização. $\mathrm{Na}$ segunda fase, o conhecimento tácito compartilhado, por exemplo, por uma equipe autoorganizada é convertido em conhecimento explícito na forma de um novo conceito, um processo semelhante à externalização. $O$ conceito criado precisa ser justificado na terceira fase, na qual a organização determina se vale realmente a pena perseguir o novo conceito. $\mathrm{Na}$ quarta fase, recebido o sinal verde, os conceitos são convertidos em um arquétipo, que pode assumir a forma de um protótipo no caso do desenvolvimento de um produto "concreto" ou em um mecanismo operacional no caso de inovações "abstratas". A última fase amplia o 
conhecimento criado, constituindo o que foi chamado de difusão interativa do conhecimento (cross-leveling of knowledge).

Figura 1 - A Espiral do Conhecimento de Takeuchi e Nonaka

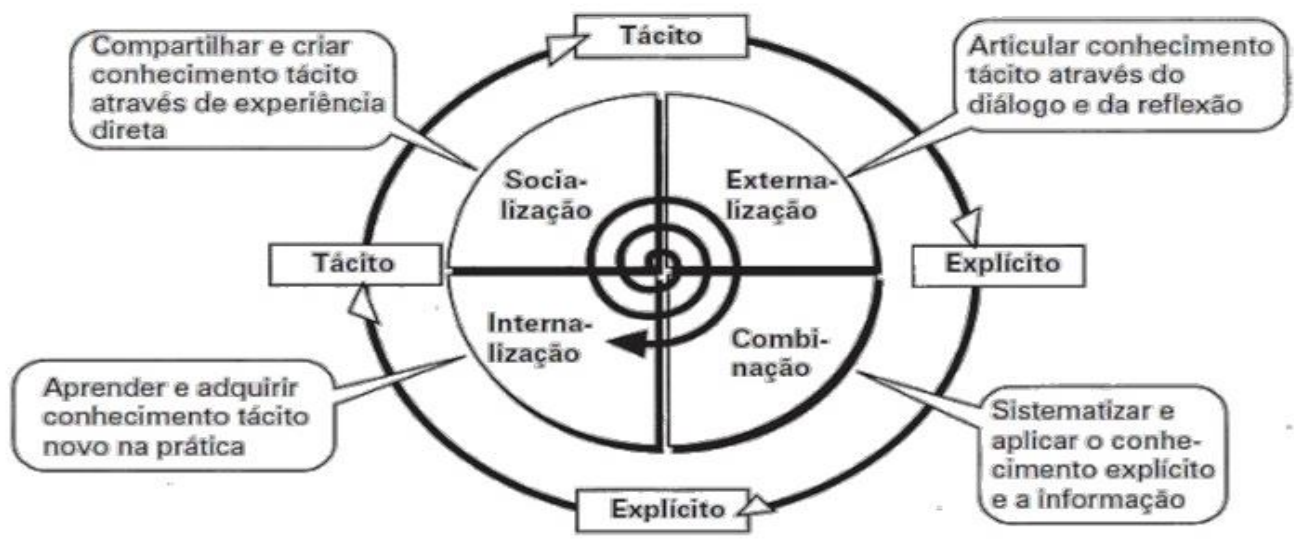

Fonte: Takeuchi e Nonaka (2008)

Todo esse processo nos leva a entender que a gestão do conhecimento é intervencionista. Como observam Probst et al. (2009), as empresas devem desenvolver seu conhecimento de modo objetivo e não o devem deixar desenvolver-se ao acaso. E completam: conhecimento não é o mesmo que cognição: ele deve demonstrar sua utilidade em aplicações práticas.

Para Salim, 2001 apud Canongia et al. (2004, p. 234) "a Gestão do Conhecimento pode ser sintetizada como um processo, articulado e intencional, destinado a sustentar ou a promover o desempenho global de uma organização, tendo como base a criação e a circulação de conhecimento."

Diante disso, Probst et al. (2009) elencou as atividades que chamou de processos essenciais de gestão do conhecimento, os quais estão relacionados entre si: identificação do conhecimento (transparência externa e interna do conhecimento), aquisição do conhecimento (formas de trazer o conhecimento de fora), desenvolvimento do conhecimento (como criar novos conhecimentos, complementa a aquisição), compartilhamento e distribuição do conhecimento (transição do conhecimento individual para o grupo ou organização), utilização do conhecimento (aplicação produtiva) e retenção do conhecimento (armazenagem do conhecimento).

Detalhando melhor esses processos de gestão do conhecimento, temos:

\section{a. Identificação do conhecimento}

Na visão de Cribb (2010), o conhecimento pode ser identificado como objeto ou como processo, sendo um objeto é passível de compra, criação, possessão ou venda. Já como processo se revela na interação entre pessoas, por meio da criatividade, inovação, motivação e comunicação.

Como destacado por Silva (2002), o grande desafio consiste em codificar o conhecimento e para isso menciona a proposta de Davenport e Prusak (1998) que é o de utilizar mapas de conhecimento, que são como arquivos que identificam onde está o conhecimento tácito e o explícito. Esse mapa pode ser constituído através do conhecimento que está embutido na mente dos funcionários, pois segundo ele: "Mapear quem conhece o 
que na organização resulta em um inventário de conhecimentos valioso [...] (SILVA, 2002, p.149)".

Para Rezende (2002), a utilização de um banco de dados de conhecimento, como páginas amarelas, permite maior acesso aos conhecimentos, sejam eles em processos, comercial, financeiro ou tecnológico. Para tanto, deve-se escolher entre as várias tecnologias de administração do conhecimento.

\section{b. Aquisição / Desenvolvimento do conhecimento}

Conforme citado por Brix apud Lyles (2014), os investimentos em pesquisa e desenvolvimento são formas de criar conhecimento interno à empresa, outra maneira de aquisição de conhecimento é a fonte externa, por meio de empregados advindos de concorrentes, com determinadas expertises.

Para Canongia (2004) a gestão da inovação é possível, por meio da aquisição de conhecimento externo à organização, buscando recursos financeiros para adquirir competências, ou vendendo as competências internas e através do compartilhamento com outras entidades como universidades, centros de pesquisa, fornecedores e seus próprios concorrentes, que venham a contribuir com o conhecimento interno da empresa.

De acordo com Silva (2002), trabalhar o conhecimento na organização está ligado a desenvolver as competências empresariais ou suas capacidades essenciais, chamadas core competence ou core capabilities.

Em se tratando de identificação e construção de core competences, Canongia (2004) destaca a importância da codificação do conhecimento, sua disseminação pela empresa e a sua aplicação, por meio de interligação dos processos, com a Pesquisa e Desenvolvimento e a produção.

Conforme bem definido por Lemos (2000), no ambiente competitivo das empresas, o mais relevante, além de ter acesso às informações, é ter habilidade para gerar novos conhecimentos (learning-to-learning), ou seja, a capacidade de aprender e utilizar o aprendizado para trazer vantagem competitiva, compartilhando entre os profissionais da organização, elevando as competências tecnológicas e organizacionais da empresa.

\section{c. Compartilhamento e distribuição do conhecimento}

Brix (2017) afirma que o nível do conhecimento evolui do individual para o grupal e então para o organizacional. O conhecimento pessoal (intuição, estudo, vocação, experiência, etc.) é interpretado por cada indivíduo do grupo e cada interpretação é integrada uma a outra e quando essa integração é completada a ideia final é institucionalizada.

\section{d. Retenção do conhecimento}

"Cada indivíduo que sair da empresa levará consigo conhecimentos que vale a pena reter, e cada novo funcionário trará conhecimentos que merecem ser compartilhados" (REZENDE, 2002, p. 126 apud STEWART, 1998).

Ademais, o capital intelectual que engloba a gestão do conhecimento pode ser gerido em forma de estoques e fluxos que possuem proteção legal, como direitos autorais, patentes e marcas. Nesse sentido, a tecnologia da informação é utilizada para reter e administrar o capital intelectual da empresa (REZENDE, 2002).

Porém, a Gestão do Conhecimento não pode se ater apenas a utilização de tecnologias de comunicação e informação. Embora gerir conhecimento perpasse pela tecnologia, ela é um processo que depende da interpretação do ambiente em que a empresa está inserida, as

Perspectivas em Gestão \& Conhecimento, João Pessoa, v. 8, número especial, p. 4-20, out. 2018. 
necessidades individuais de seus funcionários, bem como as necessidades de toda a organização, coletivamente, em criar conhecimento e de aprender (CARTONI, 2015).

A inovação não se limita a produtos e serviços desenvolvidos através de uma nova tecnologia, ela surge a partir do conhecimento que é compartilhado pelos profissionais da empresa, pois são esses que inovam. As empresas, portanto, devem valorizar a criatividade dos seus profissionais (DANTAS; MOREIRA, 2011).

\section{e. Utilização do conhecimento}

Atualmente, a revolução advinda da tecnologia da informação e a busca constante pela competitividade, imposta pela economia, tem mudado a forma como as empresas devem se organizar para trabalhar o conhecimento de forma a produzir novos produtos, processos e formas organizacionais (SILVA, 2002).

Ainda nesse raciocínio, Rezende (2002) pondera que a questão principal é a de condensar o conhecimento tácito dos profissionais com as informações organizacionais, disponíveis em base de dados, planilhas e relatórios, de forma a obter vantagem para a empresa e a questão secundária de como reter esse conhecimento, tornando-o propriedade da organização.

Canongia (2004) ressalta que para alcançar a competitividade atualmente, não basta para a empresa ter alto desempenho ou ótima técnica em seus produtos, mas depende da produção e aplicação do conhecimento, por meio de oportunidades novas e transposição de dificuldades.

Resumindo, gerir conhecimento é algo que traz resultados num médio e longo prazo, se trata de um processo, que envolve compartilhamento e utilização de conhecimentos entre as pessoas e onde as tecnologias de informação e comunicação são utilizadas como ferramentas de apoio (CARTONI, 2015).

\subsection{Os desafios e oportunidades para o cumprimento das funções da Gestão do Conhecimento}

A importância do conhecimento para a inovação nas organizações se dá por meio da exploração e interação das diversas fontes do conhecimento, utilizando para isso as ferramentas de tecnologia da informação e que propicia não só o crescimento de uma empresa, mas também a interação entre várias organizações (LEMOS, 2000).

Essa dinâmica da tecnologia, englobando o regime tecnológico e as estratégias tecnológicas, assim como as interações entre os atores e instituições é que determinam como serão os processos de aprendizagem e, influenciam na aquisição de vantagens competitivas. As interações criam vantagens positivas, que elevam a competitividade das MPEs a partir de capacitações inovadoras e de processos que estimulam o aprendizado, a concentração e a propagação de conhecimentos. Enfatizam-se os processos de aprendizado informais (learning by doing; learning by using; learning by interacting) e a disseminação tecnológica através de spillovers, mecanismos relevantes, especialmente, para as empresas que não possuem recursos para investir em laboratórios de P\&D (BELL; ALBU, 1999; MALERBA, 1992 apud DE ALMEIDA; FERRAZ CARIO, 2013).

Em se tratando de investimento, Tigre (2014) destaca que o tamanho da empresa é primordial para definir sua capacidade de investimento em P\&D. Em geral, as grandes empresas, por contarem com maiores recursos e capacitações para desenvolvimento de novos produtos e processos, concentram os investimentos em P\&D. Contudo, algumas micro e pequenas empresas conseguem ser inovadoras, especialmente em novos setores e em redes

Perspectivas em Gestão \& Conhecimento, João Pessoa, v. 8, número especial, p. 4-20, out. 2018. 
de empresas. Para essas empresas, o acesso às informações tecnológicas foram facilitadas pelas tecnologias de comunicação, como a Internet.

Nesse sentido, a tecnologia da informação é relevante na busca do conhecimento de determinado tema ou de saber onde buscá-lo, com o objetivo de armazenar e gerenciar o conhecimento da empresa e impulsionar os procedimentos inovativos. As informações e processos internos deixam de ser estocados em sistemas morosos, verticais e hierarquizados. Muitas empresas investem em TI para formação de banco de dados que reúnem conhecimentos que ficam disponíveis para consulta, de livre acesso em qualquer local, possibilitando aprimorar a gestão e trazendo retorno financeiro, como informações a respeito de concorrentes, produtos, patentes, profissionais especializados, finanças, entre outros (REZENDE, 2002).

Segundo Aranha (2016), nas últimas décadas, o conhecimento passou a pertencer às áreas de Pesquisa e Desenvolvimento (P\&D) de grandes empresas, não sendo mais exclusivo das universidades e centros de pesquisas. Com isso, essas grandes empresas passaram a investir seu capital de risco em novos empreendimentos e a inovação deixa de ser estimulada pelos governos, somente.

Importante destacar a denominada "Primeira Revolução Acadêmica", que, no final do século XIX, fez com que a universidade, que anteriormente visava apenas à atividade de ensino e transmissão do conhecimento já existente, passasse a destacar a interação entre ensino e a pesquisa, passando a serem geradoras de conhecimento, as universidades se tornaram objeto de interesse de aproximação com o setor produtivo (ETZKOWITZ, 2004).

No século XX, a relação de tríplice hélice entre universidade-indústria-governo, culmina com a chamada "grande transformação" ou a Terceira Revolução Acadêmica, onde a universidade com seu papel científico empreendedor é o epicentro da inovação. A universidade faz ciência, tecnologia e cada vez mais inovação. Há o surgimento de P\&D patrocinada por grandes empresas, universidades e governos, mudando o processo de inovação, é a chamada por Mowey e Rosenberg (1998) de "institucionalização da inovação" (ETZKOWITZ; VIALE, 2010).

De acordo com Gomes e Pereira (2015), o modelo denominado de Hélice Tríplice que representa as interações existentes entre o Governo, a Universidade e a Empresa, é onde são compartilhados os conhecimentos, produzindo a inovação como fruto dessa interação (CLOSS; FERREIRA, 2010).

Gomes e Pereira (2015) destacam que, na relação decorrente da hélice tríplice que compreende empresas, universidades e governos há fatores a serem levados em consideração: políticas governamentais, formas de contrato, cultura organizacional, vantagens e barreiras. Outro fator relevante é o registro de patentes e transferência de tecnologia que deve ser melhor compreendido entre os atores da hélice tríplice, especialmente, entre as universidades que desenvolvem a tecnologia mas que dependem da relação com o setor produtivo para que suas criações se revertam em benefícios para a sociedade (IPIRANGA et al., 2010).

Assim, analisando o Sistema Nacional de Inovação brasileiro, nota-se que ainda há necessidade de aprimorar a relação entre o ambiente acadêmico e empresarial, resultando em um trabalho mais complementar e coordenado. Segundo Calmanovici (2011, p. 201): "No Brasil, ainda não há total coerência estratégica entre o investimento público e o privado em PD\&I". Esses investimentos não se misturam e, às vezes, até competem. No Brasil, as empresas ainda se utilizam pouco do que é investido pelo governo em ICTs, nem direta ou indiretamente. Não há uma discussão, entre empresas e o ambiente acadêmico, o que gera divergências em torno das prioridades e causa um certo descompasso entre os investimentos (CALMANOVICi, 2011).

Nesse ponto, cabe destacar o relevante papel das incubadoras de empresas. De acordo com Baêta et al. (2006), a atuação das incubadoras como apoio a criação de pequenas e

Perspectivas em Gestão \& Conhecimento, João Pessoa, v. 8, número especial, p. 4-20, out. 2018. 
médias empresas, além de promover o desenvolvimento dessas organizações, buscam levar aos gestores capacitação para a gestão do empreendimento. Numa comparação entre as empresas instaladas em uma incubadora com outras que não passaram pelo mesmo processo, os autores acreditam que as incubadas possuem maior chance de sobrevivência, quando inseridas no mercado.

De acordo com a definição apresentada por Raupp e Beuren (2011, p. 331), "As incubadoras apresentam um importante papel socioeconômico já que conseguem, na maioria das vezes, reunir em um mesmo ambiente diversas facilidades, desde auxílio na obtenção de financiamentos até apoio administrativo e de estrutura".

\subsection{A inovação como fator de competitividade}

Conforme apontado por Santos et al. (2011), o tema inovação começou a ser discutido, a partir do século XX, e Schumpeter foi o primeiro autor a discutir sobre o assunto, abordado dentro da chamada teoria do desenvolvimento econômico, naquele momento o autor diferenciou invenção e inovação: "uma invenção é uma ideia, esboço ou modelo para um novo ou melhorado artefato, produto, processo ou sistema. Uma inovação, no sentido econômico somente é completa quando há uma transação comercial envolvendo uma invenção e assim gerando riqueza“" (SCHUMPETER, 1988).

E os autores prosseguem relatando os conceitos de inovação:

Autores chamados de neoschumpeterianos vêm reforçar o pensamento de Schumpeter com relação à importância da inovação para o desenvolvimento econômico no século XXI.

Rieg e Alves Filho (2003) definem inovação, a nível empresarial, a partir das inovações tecnológicas de processos e produtos comercialmente viáveis, uma consequência dos esforços tecnológicos realizados pelas organizações. Estas inovações podem ser tanto significativas como incrementais. As inovações significativas relacionam-se a produtos ou processos totalmente novos, que não possuam semelhantes aos já existentes até aquele momento. Já as inovações de produtos ou processos incrementais resultam de aperfeiçoamentos de produtos que já existem e que podem ser melhorados. Os autores ainda discutem que para medir a inovação a nível empresarial deve se considerar as inovações em produtos e processos, quantitativamente, como a parcela do faturamento decorrente das inovações, além do número de patentes conquistadas (SANTOS et al., 2011).

Ampliando os sentidos sobre inovação, Johannessen, Oslan e Lumpkin (2001) associam inovação com a ideia de novidade. Eles ressaltam que a inovação pode ocorrer como: novos produtos, novos serviços, novos métodos de produção, abertura para novos mercados, novas fontes de fornecimento e novas maneiras de se organizar (SANTOS et al., 2011).

Como destacam Santos et al. (2011) a inovação faz parte de um processo que pode ser complexo e que pode ser relacionado com a descoberta, desenvolvimento, experimentação e adoção de novos produtos e/ou processos produtivos (DOSI et al., 1990).

Por sua vez, Druker (1989) conceitua inovação como forma de diferenciação no mercado. Porém, ao inovar não há certeza de sucesso, ou seja, o produto inovador pode dar certo ou ser um total fracasso (SANTOS et al., 2011).

Por fim, Tom Kelly (2005), membro executivo da H. Business School da Universidade da Califórnia em Berkeley, nos Estados Unidos, destaca a criatividade e a diversidade como importantes para inovação. Para ele, inovação é consequência de um trabalho em equipe que considera a cultura e as tendências de mercado, destinados ao futuro em forma de produtos e serviços realmente diferenciados (SANTOS et al., 2011).

Outra distinção importante é a de inovação radical e incremental, a diferença entre as duas se dá na medida em que a inovação incremental busca um aperfeiçoamento de algo já existente, enquanto a inovação radical busca novas tecnologias que resultam em um produto

Perspectivas em Gestão \& Conhecimento, João Pessoa, v. 8, número especial, p. 4-20, out. 2018. 
ou serviço completamente novo, ou produzido por meio de um processo novo, ou a interação entre produtos e processos. (FONSECA et al., 2012)

Para efeito desta pesquisa, ficaremos com a definição apresentada pelo INPI. "A inovação refere-se à capacidade de transformar uma invenção em um produto ou processo negociável. [...] Para ser patenteável, deve-se comprovar que uma invenção ou um modelo de utilidade pode ser aplicável industrialmente ou explorada no mercado. Uma invenção não pode ser um simples fenômeno teórico; deve ser útil e produzir uma vantagem prática" (INPI, 2013, p. 6; INPI, 2013, p. 18).

De acordo com Brinkhues e Cunha (2009), para que se tenha vantagem competitiva é necessário que a empresa tenha uma estratégia de criação de valor única, isto é, nenhuma outra empresa possui, ao mesmo tempo. Quando outras empresas não podem copiar os benefícios dessa estratégia de criação de valor, então essa vantagem competitiva é sustentável. Todavia, essa vantagem não dura para sempre, pois podem acontecer alterações estruturais na indústria e alterar o que são recursos relevantes (BARNEY, 1991). Nesse sentido, Barney define quatro atributos para que um recurso tenha potencial para gerar vantagem competitiva sustentável, são eles: ser valioso, raro, não substituível e imperfeitamente imitável.

Nesse sentido Dantas e Moreira (2011) afirmam que o processo de inovação, se compõe de quatro fases, que tem como base o conhecimento anterior à criação de um produto ou serviço. As quatro fases, relativamente sobrepostas, são: reflexão estratégica, geração de novas soluções, implementação e difusão. Estas quatro grandes fases do processo de inovação englobam as seguintes etapas: exploração, investigação, desenvolvimento, engenharia, industrialização e comercialização. Claramente, não existe uma primeira nem uma última fase: a gestão da inovação consiste na gestão global e interativa, articulando as diversas etapas do processo de inovação.

Partindo do pressuposto que o avanço tecnológico é uma realidade atual, e que as empresas são diferentes e se inserem em ambientes competitivos e em constante mutação, que cada empresa utiliza estratégias organizacionais distintas, existe a necessidade de criar estruturas capazes de manter essas estratégias, os gestores precisam investir em recursos estratégicos e desenvolver capacidades para as empresas competirem no mercado em condições de alcançar a vantagem competitiva e a performance superior (VALLANDRO; TREZ, 2013).

\subsection{O papel da Proteção Industrial nas Micro e Pequenas Empresas}

Ponto relevante levado em consideração pelos capitalistas de risco é a propriedade intelectual. A patente agrega valor ao empreendimento, e quanto mais valiosa, considerando os custos dessa proteção, maior atratividade junto aos investidores. Porém, as questões que envolvem a proteção da propriedade intelectual devem ser entendidas até pelo próprio inventor que está realizando sua pesquisa num centro de pesquisa ou numa universidade (CARDULLO, 2010).

As PMEs, em sua maioria, não dão o valor adequado a Propriedade Intelectual (PI), como oportunidade de aumentar seu lucro. Porém, a PI se torna de grande valor quando é protegida legalmente e os produtos e/ou serviços associados a ela são requisitados no mercado (SUKARMIJAN e SAPONG, 2013).

Para Cardullo (2010), os capitalistas de risco, objetivando o retorno financeiro dos seus investimentos têm observado o aumento de valor da empresa, decorrente da detenção do direito de propriedade intelectual atribuído a ela, pois o direito de PI pode alavancar o crescimento nos mercados.

Perspectivas em Gestão \& Conhecimento, João Pessoa, v. 8, número especial, p. 4-20, out. 2018. 
Porém, Sukarmijan e Sapong (2013) observam que, por outro lado, para as PMEs o direito de $\mathrm{PI}$ envolvem custos que podem ser maiores que seus benefícios, tendo em vista que grande parcela de investimento deve ocorrer antes mesmo do produto estar no mercado e que o apoio financeiro dos investidores ou do governo não incluem, em sua maioria, a proteção dos direitos de PI (IDRIS, 2003).

E talvez por isso, as MPEs brasileiras, ainda não exploram como deveriam a proteção de $\mathrm{PI}$, ou seja, o seu conhecimento e a sua tecnologia nos seus planos de negócio, um dos motivos seria a falta de conhecimento sobre o assunto, ou por não perceberem o valor desses ativos no mercado. E isso, pode comprometer a atuação da empresa (GONÇALVES; PROENÇA, 2011).

Segundo a publicação do INPI - Inventando o Futuro: uma Introdução às Patentes para as Pequenas e Médias Empresas - uma patente pode ser considerada como "um direito exclusivo concedido pelo Estado relativamente a uma invenção (ou modelo de utilidade), que atende ao requisito de novidade, envolve uma atividade inventiva (ou ato inventivo) e é suscetível de aplicação industrial" (INPI, 2013, p. 3). E ressalta, o objeto que resulte em uma patente de invenção ou de um modelo de utilidade deve possuir os requisitos de: ser algo totalmente novo, advir de uma atividade/ato inventivo e possuir aplicação industrial.

Porém, como ressaltado na série mencionada, muitas das vezes, aperfeiçoamentos técnicos simples e baratos, mas com grande aceitação no mercado, geram lucros consideráveis para seus inventores e/ou empreendedores. Apesar disso, a maioria das patentes provém de estudos e pesquisas, que requerem grandes investimentos na área de P\&D das empresas, a longo prazo. Contudo, o INPI ressalta que antes de depositar um pedido de patente, a empresa deve considerar se a invenção pode resultar em um produto economicamente rentável e aceito no mercado. Devido aos custos decorrentes de um depósito de patente, que engloba também, mais tarde, sua manutenção, a empresa deve avaliar a relação custo $\mathrm{x}$ benefício em se ter uma patente ou não, tendo em vista o elevado investimento (INPI, 2013).

No entendimento de Dantas e Moreira (2011) a existência de um direito de PI, pode atrair investimentos que poderão ser utilizados na inserção do novo produto ou serviço no mercado. E finalizam ressaltando que as empresas são responsáveis pela criação de riqueza numa sociedade. Ao protegerem, por meio dos direitos de $\mathrm{PI}$, novos processos e produtos, as empresas adquirem por certo tempo, o monopólio no mercado e com isso são capazes de deter de alguma forma de controle sobre os preços ou sobre as formas de comercialização dos seus processos ou produtos, que resultam em lucro.

Porém, como complementar a concessão de patentes e considerado como meio alternativo de proteger as invenções, o segredo de negócio, é utilizado pelos depositantes de patentes para garantir o segredo de suas invenções até a publicação oficial do pedido da patente pelo INPI (INPI, 2013).

Contudo, afirma Cardullo (2010, p. 3), "o valor econômico de uma patente, de uma marca comercial, de um software, de um nome de domínio e de qualquer propriedade intelectual deve ser cuidadosamente ponderado na análise de quais empresas merecem receber investimentos em capital de risco".

Em resumo, só a empresa pode decidir qual proteção é a mais viável para proteger uma invenção, levando em conta os investimentos envolvidos em um depósito de patente. Mas, as empresas devem considerar as vantagens significativas que poderão ser obtidas por meio de uma proteção de $\mathrm{PI}$. A decisão deve ponderar qual a alternativa é mais útil comercialmente (INPI, 2013). 


\section{RESULTADOS}

\subsection{Caracterização da empresa BHS}

A BHS Comércio de Produtos Para Saúde Ltda - EPP (Brasil Health Service ${ }^{\circledR}$ ) é uma empresa de pequeno porte, localizada em São Paulo. A empresa iniciou suas atividades no ano de 2001 e já esteve incubada na Universidade de São Paulo (USP). Desde o início o projeto da empresa pretendia atender a indústria farmacêutica, trabalhando com produtos médicos promocionais.

Atualmente, com 17 (dezessete) anos de mercado, a empresa tem como atividade econômica principal o comércio atacadista de instrumentos e materiais para uso médico, cirúrgico, hospitalar e de laboratórios. Atende a grandes laboratórios e indústrias farmacêuticas. Possui 14 (quatorze) funcionários em seu quadro fixo e 6 (seis) colaboradores eventuais, dentre esses tem farmacêuticos, médico, mestres e doutores.

\subsection{A interação entre conhecimento e inovação na empresa BHS}

Comparando o que foi relatado na entrevista realizada na empresa, é possível observar os pontos que foram destacados também na literatura. Primeiramente, cabe destacar a importância do compartilhamento do conhecimento tácito dos profissionais, lembrando que a partir da troca de experiências que o conhecimento é compartilhado. O que reforça a teoria de que o conhecimento gera a inovação. A empresa aponta a necessidade da troca de experiências de forma constante, no dia a dia e nas participações em congressos e outros eventos científicos.

Nesse sentido, Da Silva (2016) ressalta que num mundo de muitas mudanças, as organizações mudam por meio das pessoas e do conhecimento que elas têm, dessa forma é possível criar conhecimento ou retê-lo. O que as empresas têm de mais valioso é a união do conhecimento adquirido com as experiências (tácito) com aquele que é formal, armazenável e pode ser transportado (explícito).

E prossegue Da Silva $(2016$, p. 4) "nos dias de hoje, o conhecimento criado e fomentado nas organizações, através do compartilhamento coletivo entre o tácito e o explícito, representa práticas estratégicas de negócios empresariais, visto que adotam este novo modelo de gestão."

Outro ponto relevante a ser apontado diz respeito à tecnologia, as empresas de base tecnológica, assim como descrito na literatura, são empresas que tem grande destaque no mercado e melhor acesso ao mercado internacional. E nesse caso, a universidade possui papel primordial, a partir do momento que deixam de focar apenas em aspectos acadêmicos e buscam também transformar seus conhecimentos em propriedade intelectual. $O$ fato da empresa entrevistada ter sido incubada em um centro tecnológico de uma universidade trouxe vantagens singulares, em relação a outras que não possuem essa experiência, pois além das pesquisas desenvolvidas nesse ambiente, se valem de outras vantagens como o financiamento de longo prazo para seus projetos, custos consideravelmente mais baixos de instalação da empresa, além de acesso a outras empresas que possam gerar novas ideias e produtos.

Sobre a relação com a universidade, vale destacar o que é ressaltado por Vedovello (2000) de que cada vez mais tem se notado e discutido que a maior interação entre universidade-indústria, pode trazer mais benefícios pra ambos e alavancar a competitividade industrial dos países, pois tem se tornado mais formal e frequente e interessante para os governos e planejadores, tanto em países desenvolvidos como em desenvolvimento, pois essa interação ainda é considerada um recurso científico-tecnológico subutilizado.

Perspectivas em Gestão \& Conhecimento, João Pessoa, v. 8, número especial, p. 4-20, out. 2018. 
Para Etzkowitz (2001), essa nova interação entre universidade e indústria, tem como foco o desenvolvimento de pesquisa científica e a criação de mecanismos de abrangência de fronteiras, entre eles a criação de escritórios de transferência de tecnologia e empresas derivadas.

As informações sobre a longevidade das micro e pequenas empresas também foi um fato obervado e por esse motivo a empresa busca sempre inovar, levando em consideração também o ciclo de vida dos produtos, que conforme citado na literatura, tem se tornado cada vez mais curto.

Tendo em vista todas as fases ou etapas que envolvem o processo de inovação e, considerando o dispêndio de recursos, especialmente financeiro, em todo o processo, cabe ressaltar o que afirmam Dantas e Moreira (2011), embora inovar seja arriscado é necessário que a empresa que quer ser competitiva e se manter no mercado, inclua a inovação como objetivo principal da empresa. Claramente, não inovar é estagnar.

Há um destaque especial para a dificuldade das MPEs em obter financiamentos para operacionalizar seus projetos. E a limitação no que diz respeito às inovações, que partem de necessidades do mercado e não de pesquisas contínuas como nos demonstra a literatura, tendo em vista a dificuldade financeira que essas empresas enfrentam. Uma dessas dificuldades enfrentadas é a manutenção dos profissionais, por não terem condições financeiras de reter alguns deles, que porventura recebem outras propostas profissionais, o que acarreta um atraso nas pesquisas.

Em se tratando de financiamento, segundo Nascimento (2004) a dificuldade de financiamento no Brasil, pelas empresas, é um fator crítico e real, as principais barreiras enfrentadas são o acesso ao crédito, os prazos de pagamento e os juros, que está entre os mais elevados do mundo (MEIRELLES et al., 2008).

Mas, apesar das dificuldades, a empresa BHS demonstra perceber a importância de gerir o conhecimento internamente, e para isso mantém os profissionais especializados (mestres e doutores) em seu quadro de funcionários. Cabe apontar que as inovações desenvolvidas pela empresa são produtos de média e alta complexidade, com enorme grau tecnológico, e que por conta disso requerem profissionais altamente capacitados, durante a pesquisa e desenvolvimento, além do tempo despendido durante todo o processo, já que as pesquisas podem durar anos.

Assim, para criar uma vantagem competitiva, que se traduza em retorno financeiro, a empresa deve introduzir uma inovação tecnológica (voltada para produto, materiais ou processos) ou inovação no seu modelo de negócio (voltada para aspectos de gestão ou criação de mercados) (CONTO, S. M. et al., 2016).

Essa dinâmica faz com que as empresas estejam sempre em busca de inovações, sejam inovações nos processos, produtos, organização da produção e formas de comercialização. 0 resultado dependerá das capacidades internas da empresa, de sua competência organizacional e da sua qualificação produtiva (Ferraz et al., 1995) (CONTO, S. M. et al., 2016).

Enfim, o sucesso e sobrevivência de uma empresa decorrem da vantagem competitiva que ela adquire ao inovar em seus produtos ou processos e embora as MPEs enfrentem obstáculos é possível que obtenham essa vantagem, apostando na inovação (PEREIRA et al., 2009).

No que diz respeito às patentes, a BHS reconhece e valoriza sua importância, porém ressalta seu elevado custo ainda com grande impacto para a empresa, além do prazo de análise e concessão do pedido de patente, que ainda é altamente moroso.

Nesse sentido, Sukarmijan e Sapong (2013) apontam, as barreiras enfrentadas pelas MPEs para utilização do sistema de $\mathrm{PI}$, de forma que Ihes traga benefícios. Uma dessas barreiras seria a falta de divulgação do sistema de $\mathrm{PI}$, com vistas a essas empresas, as MPEs acabam por não utilizar, não somente as patentes, mas também as outras formas de proteção,

Perspectivas em Gestão \& Conhecimento, João Pessoa, v. 8, número especial, p. 4-20, out. 2018. 
como modelos de utilidade, marcas comerciais, desenhos industriais, segredos comerciais e outros direitos de propriedade intelectual (SALEH, 2008). Outra limitação seria a dificuldade de obtenção de recursos humanos capazes de entender e aconselhar no que diz respeito ao sistema de $\mathrm{PI}$, tendo em vista sua complexidade, ou seja, profissionais capazes de absorver todo o processo de pedido de registro / concessão de direitos de PI. Não menos limitador são os custos que envolvem a aquisição, manutenção e aplicação de um direito de $\mathrm{PI}$, ainda mais para empresas que atuam em diversos mercados e em regiões distintas e dispersas. Como último fator de limitação estão as imitações fraudulentas e os produtos pirateados.

Quadro 1 - Relação entre a empresa entrevistada e os processos essenciais da Gestão do Conhecimento

\begin{tabular}{|l|l|}
\hline \multicolumn{1}{|c|}{$\begin{array}{c}\text { PROCESSOS ESSENCIAIS DA } \\
\text { GESTÃO DO CONHECIMENTO }\end{array}$} & \multicolumn{1}{|c|}{ Empresa BHS } \\
\hline IDENTIFICAÇÃO & $\begin{array}{l}\text { Conhecimento visto como um processo derivado da interação } \\
\text { entre as pessoas }\end{array}$ \\
\hline \multirow{2}{*}{ AQUISIÇÃO/DESENVOLVIMENTO } & $\begin{array}{l}\text { Investe em P\&D internamente, além de parcerias com } \\
\text { universidades e associações com outras empresas }\end{array}$ \\
\cline { 2 - 2 } & $\begin{array}{l}\text { Explora suas competências internas, buscando inovar em seus } \\
\text { produtos ou processos, investindo em pesquisas específicas }\end{array}$ \\
\hline \multirow{2}{*}{ COMPARTILHAMENTO E } & $\begin{array}{l}\text { O conhecimento parte inicialmente de um ou dois indivíduos é é } \\
\text { compartilhado dentro da empresa, em busca do } \\
\text { desenvolvimento de novos produtos, por meio das pesquisas } \\
\text { realizadas e envolve praticamente toda a empresa }\end{array}$ \\
\hline \multirow{2}{*}{ RETENÇÃO } & $\begin{array}{l}\text { Oferece participação direta ou indireta aos profissionais } \\
\text { Quando se trata de retenção de profissionais, ressalta a } \\
\text { dificuldade de competir financeiramente com outras propostas, } \\
\text { porventura recebidas, pelos seus funcionários }\end{array}$ \\
\hline UTILIZAÇÃO & $\begin{array}{l}\text { Não demonstrou utilizar ferramentas práticas e objetivas para } \\
\text { transferir o conhecimento tácito dos seus profissionais e } \\
\text { incorporá-lo na organização, com exceção das patentes, que é de } \\
\text { propriedade da empresa e contém conhecimento passível de } \\
\text { produção }\end{array}$ \\
\hline
\end{tabular}

Fonte: Elaborado pelos autores

\section{CONSIDERAÇÕES FINAIS}

O presente estudo tinha como objetivo final examinar o processo de gestão do conhecimento envolvendo uma empresa de pequeno porte que resultou em depósito de patente. Por meio da entrevista realizada foi possível analisar como o processo de gestão do conhecimento e da inovação se dá no ambiente dessa pequena empresa.

Apesar de buscar manter os profissionais em seu quadro, tanto quanto possível, de forma a manter e distribuir o conhecimento dos mesmos, conclui-se que a empresa entende a crucial importância da gestão do conhecimento, no desenvolvimento de inovações, porém não possui práticas ou métodos claros para realizá-la internamente. Entretanto, a empresa BHS apresenta uma política de participação direta ou indireta na empresa, forma encontrada para captar conhecimento de forma contínua ou ao menos, mantendo uma rede de profissionais em torno da empresa.

A importância da parceria com a universidade, bem como os órgãos de apoio as MPEs se dá pelo fato de utilizar o conhecimento gerado naquele ambiente, o acesso e participação de profissionais especializados (mestres e doutores) fazendo com que o conhecimento gerado

Perspectivas em Gestão \& Conhecimento, João Pessoa, v. 8, número especial, p. 4-20, out. 2018. 
no meio acadêmico seja compartilhado e transformado, na prática, em um produto ou processo.

Também foi possível observar que há na empresa um grande envolvimento com a questão da gestão do conhecimento, valorizando o conhecimento dos seus profissionais e tentando manter a sinergia de rede daqueles que participam esporadicamente do seu quadro, os chamados profissionais de apoio. Da mesma forma, a empresa destaca a importância das inovações e a posterior obtenção de patentes dos produtos desenvolvidos. Fica claro que a empresa tem intenção de ampliar seu mercado e atingir o mercado internacional, onde as patentes garantem um diferencial competitivo.

Porém, após a entrevista realizada com a empresa BHS e os resultados apresentados, cabe mencionar a limitação encontrada no presente estudo e que poderiam vir a ser objeto de outros estudos futuros. A empresa foi incubada em uma universidade, fato que deu a ela maior proximidade e acesso às pesquisas e novas tecnologias, além de facilitar o acesso ao financiamento de recursos para sua manutenção e desenvolvimento. Apesar dessa limitação, entende-se que o presente trabalho atingiu os objetivos propostos.

\section{REFERÊNCIAS}

ARANHA, José Alberto Sampaio. Mecanismos de geração de empreendimentos inovadores [Recurso eletrônico on-line]: mudança na organização e na dinâmica dos ambientes e o surgimento de novos atores. Brasília, DF: ANPROTEC, 2016.

BAÊTA, A. M. C.; BORGES, C. V.; TREMBLAY, D. G. Emprendedorismo nas incubadoras: Reflexões sobre tendências atuais. Revista Comportamento Organizacional e Gestão v.12, n. 1, p. 7-18, 2006.

BEM, Roberta Moraes de; RIBEIRO JUNIOR, Divino Ignácio. A gestão do conhecimento dentro das organizações: a participação do bibliotecário. p. 75-82 Revista ACB, [S.I.], v. 11, n. 1, p. 7582, nov. 2006. ISSN 1414-0594. Disponível em: https://revista.acbsc.org.br/racb/article/view/468. Acesso em: 04 ago. 2017.

BRINKHUES, R. A.; CUNHA, M. A. V. C. da. Vantagem competitiva e o uso das tecnologias de informação e comunicação: estudo na cadeia produtiva do vinho do Rio Grande do Sul. REBRAE. Revista Brasileira de Estratégia, Curitiba, v. 2, n. 3, p. 291-305, set./dez. 2009.

BRIX, Jacob. Exploring knowledge creation processes as a source of organizational learning: A longitudinal case study of a public innovation project. Scandinavian Journal of Management, v. 33, n. 2, p. 113-127, 2017.

CALMANOVICl, C. E. A inovação, a competitividade e a projeção mundial das empresas brasileiras. Revista USP, São Paulo, n. 89, p. 190-203, março/maio 2011.

CANONGIA, Claudia et al. Foresight, inteligência competitiva e gestão do conhecimento: instrumentos para a gestão da inovação. Gestão \& Produção, 2004.

CARDULLO, Mario W. Intellectual Property - The Basis for Venture Capital Investments. WIPO, junho, 2010.2 Disponível em: http://www.wipo.int/sme/en/documents/venture capital investments fulltext.html. Acesso em 15 de fev. 2017.

Perspectivas em Gestão \& Conhecimento, João Pessoa, v. 8, número especial, p. 4-20, out. 2018. 
CARTONI, Daniela Maria. Gestão do conhecimento como ferramenta de estratégia organizacional. Revista de Ciências Gerenciais, v. 10, n. 12, p. 96-105, 2015.

CONSONI, Diogo José et al. A inovação como vantagem competitiva no setor automobilístico. Jovens Pesquisadores-Mackenzie, v. 3, n. 1, 2010.

CONTO, S.; JÚNIOR, J.; VACCARO, G. A inovação como fator de vantagem competitiva: estudo de uma cooperativa produtora de suco e vinho orgânicos. Gestão e Produção, v. 23, n. 2, p. 397-407, 2016.

CRIBB, André Yves. Uma abordagem integrativa de avaliação da inovação. In: Embrapa Agroindústria de Alimentos-Artigo em anais de congresso (ALICE). In: CONFERENCIA IBEROAMERICANA EN SISTEMAS, CIBERNÉTICA E INFORMÁTICA, 13.; SIMPOSIUM IBEROAMERICANO EN EDUCACIÓN, CIBERNÉTICA E INFORMÁTICA, 11., 2014, Orlando. Memorias... Winter Garden: International Institute of Informatics and Systemics, 2014. p. 200205.

CRIBB, André Y. Uma Abordagem Pragmática de Construção de Estratégias de Gestão do Conhecimento em Organizações. Revista Sistemas, Cibernética e Informática, vol. 7. N. 1, 2010.

CRUZ, L. B. Inovação Tecnológica e Vantagem Competitiva no Setor de Telefonia Móvel. 261 fls. Dissertação - Universidade Federal do Rio Grande do Sul - UFRGS. Porto Alegre, 2004.

CRUZ, Guillermo; PRATES, Caroline; SILVA ESTEVES, Priscila. The Incubation Process and the Strengthening of the Firm: a Study in Brazilian Companies. Journal of Technology Management \& Innovation, Santiago, v. 8, n. 3, p. 70, nov. 2013 . Disponível em http://www.scielo.cl/scielo.php?script=sci arttext\&pid=S07187242013000400007\&lng=es\&nr $\underline{\mathrm{m}=\text { iso. }}$. Acessado em: 03 jul. 2017.

DANTAS, José; MOREIRA, António Carrizo. O processo de inovação. Lisbon: Lidel, 2011.

DA SILVA, Mônica R. Gestão do Conhecimento: Estratégia para competitividade nas organizações. XII Congresso Nacional de Excelência em Gestão. 29 a 30 de setembro, 2016. Disponível em: http://www.inovarse.org/sites/default/files/T16 M 05.pdf. Acesso em: 04 de ago. 2017.

DE ALMEIDA, Carla Cristina Rosa, FERRAZ CARIO, Silvio Antonio, Capacitação e inovação tecnológica em micro e pequenas empresas: estudo de uma aglomeração produtiva de transformados plásticos no estado de Santa Catarina, Brasil. Revista Iberoamericana de Ciencia, Tecnología y Sociedad - CTS [en linea] 2013, 8 (Setembro): [Consulta: 6 de março de 2017] Disponível em: http://www.redalyc.org/articulo.oa?id=92429917013. ISSN 1668-0030.

ETZKOWITZ, H. The second academic revolution and the rise of entrepreneurial science. IEEE. Technology and Society Magazine, v. 20, n. 2, p. 18-29, 2001.

ETZKOWITZ, H.; LEYDESDORFF, L. The Dynamics of Innovation: From National Systems and "Mode 2" to a Triple Helix of University-Industry-Government Relations. Research Policy, v. 29, n. 2, 2000, p. 109-123.

Perspectivas em Gestão \& Conhecimento, João Pessoa, v. 8, número especial, p. 4-20, out. 2018. 
ETZKOWITZ, H; VIALE, R. Polyvalent Knowledge and the Entrepreneurial University: A Third Academic Revolution? Revista Critical Sociology, v. 36, Issue 4, p. 595 - 609. First published date: July-07-2010.

FERRARI, Alfonso Trujillo. Metodologia da Ciência. 2. ed. Editora Kennedy, Rio de Janeiro, 1974.

FONSECA, R. Competitividade e Inovação. Revista Cultura e Cidadania. Maio, 2012. Disponível em: $\quad$ https://revistaculturacidadania.blogspot.com.br/2012/05/artigos-competividade-einovacao.html?m=0. Acesso em 04 de junho de 2017.

GOMES, C. M.; KRUGLIANSKAS, I. A influência do porte no comportamento inovador da empresa. Revista de Administração e Inovação, v. 6, n. 2, art. 6, p. 5-27, 2009.

GOMES, Myller Augusto Santos; PEREIRA, Fernando Eduardo Canziani. Hélice Tríplice: Um ensaio teórico sobre a relação Universidade-Empresa-Governo em busca da inovação. International Journal of Knowledge Engineering and Management (IJKEM), v. 4, n. 8, p. 136-155, 2015.

GONÇALVES, Ada; PROENÇA, Adriano; [et al.]. Manual de Gestão para MPEs Inovadoras. Rede de Tecnologia e Inovação do Rio de Janeiro, 2011.

INSTITUTO NACIONAL DA PROPRIEDADE INDUSTRIAL (Brasil). Inventando o futuro: uma introdução às patentes para as pequenas e médias empresas/ Instituto Nacional da Propriedade Industrial. - Rio de Janeiro: INPI, 2013 (Série sobre a Propriedade Intelectual e as Atividades Empresariais, 3).

LAKATOS, Eva Maria; MARCONI, Marina de Andrade. Fundamentos de metodologia científica. - 5. ed. - São Paulo: Atlas 2003.

LEMOS, Cristina. Inovação na Era do Conhecimento. Revista Parcerias Estratégicas, n. 8, 2000. Disponível em: http://seer.cgee.org.br/index.php/parcerias estrategicas/article/viewFile/104/97. Acesso em 04 de ago. 2017.

MEIRELLES, J. L. F.; PIMENTA JÚNIOR, T.; REBELATTO, D. A. do N. Venture capital e private equity no Brasil: alternativa de financiamento para empresas de base tecnológica. Revista Gestão da Produção v. 15, n. 1, p.11-21, São Carlos, jan/abr, 2008.

NONAKA, Ikujiro; TAKEUCHI, Hirotaka. Criação de conhecimento na empresa: como as empresas japonesas geram a dinâmica da inovação. Rio de Janeiro: Campus, 1997.

PEREIRA, M. F.; GRAPEGGIA, M.; EMMENDOERFER, M. L.; TRÊS, D. L. Fatores de inovação para a sobrevivência das micro e pequenas empresas no Brasil. Revista de Administração e Inovação, v. 6, n. 1, art. 72, p. 50-65, 2009.

PROBST, Gilberto; RAUB, Steffen; ROMHARDT, Kai. Gestão do conhecimento: os elementos construtivos do sucesso. Bookman, 2009.

Perspectivas em Gestão \& Conhecimento, João Pessoa, v. 8, número especial, p. 4-20, out. 2018. 
RAUPP, Fabiano Maury; BEUREN, Ilse Maria. Perfil do suporte oferecido pelas incubadoras brasileiras às empresas incubadas. REAd. Rev. eletrôn. adm., Porto Alegre, v. 17, n. 2, p. 330359, Agosto $2011 . \quad$ Disponível em: http://www.scielo.br/scielo.php?script=sci arttext\&pid=S1413-

3112011000200002\&lng=en\&nrm=iso. Acesso em: 4 Junho de 2017.

REZENDE, Yara. Informação para negócios: os novos agentes do conhecimento e a gestão do capital intelectual. Revista Ciência da Informação, v. 31, n.2. p. 120-128, Brasília, maio/ago. 2002. Disponível em: http://www.scielo.br/scielo.php?pid=S0100$19652002000100008 \&$ script=sci abstract\&tlng=pt. Acesso em: 04 de ago. 2017.

SANTOS, Adriana B. A dos; FAZION, Cíntia B. e MEROE, Giuliano P. S. de Inovação: um estudo sobre a evolução do conceito de Schumpeter. Revista PUC, São Paulo. v. 5, n. 1, 2011.

SILVA, Sergio Luis da. Informação e competitividade: a contextualização da gestão do conhecimento nos processos organizacionais. Ci. Inf. v. 31, n. 2, p.142-151, 2002.

SUKARMIJAN, S.S.; SAPONG, O. V. The importance of intellectual property for SMEs; Challenges and moving forward. International Agribusiness Marketing Conference 2013, IAMC 2013, 22-23 October 2013, Kuala Lumpur, Selangor, Malaysia.

TERRA, José Claúdio C. Gestão do Conhecimento: o grande desafio empresarial! Elsevier, 2005.

TIGRE, Paulo Bastos. Gestão da Inovação: a economia da tecnologia no Brasil. Elsevier, 2014.

VALLANDRO, Luiz Felipe Jostmeier; TREZ, Guilherme. Visão baseada em recursos, estratégia, estrutura e performance da firma: uma análise das lacunas e oportunidades de pesquisas existentes no campo da administração estratégica. Análise. Revista de Administração da PUCRS, [S.I.], v. 24, n. 1, p. 79-81, jul. 2013. Disponível em: http://revistaseletronicas.pucrs.br/ojs/index.php/face/article/view/18785. Acesso em: 06 mar. 2017.

VEDOVELLO, Conceição. Aspectos Relevantes de Parques Tecnológicos e Incubadoras de Empresas. Revista do BNDES, Rio de Janeiro, v. 7, n. 14, p. 273-300, dez., 2000.

YIN, ROBERT K. Estudo de caso: planejamento e métodos. Robert K. Yin. Trad. Daniel, 2001.

Artigo recebido em 09/10/2018 e aceito para publicação em 29/10/2018 